\title{
DE TERRITORIOS, FRONTERAS E INMIGRANTES. REPRESENTACIONES TRANSLOCALES EN LA CHIMBA, SANTIAGO DE CHILE
}

\author{
ABOUT TERRITORIES, FRONTIERS AND INMIGRANTS. TRANSLOCAL \\ REPRESENTATIONS IN LA CHIMBA, SANTIAGO DE CHILE
}

\author{
Francisca Márquez B. ${ }^{1}$
}

\begin{abstract}
Se pregunta por la construcción del habitar en los territorios de frontera a partir de la descripción e interpretación de representaciones translocales de inmigrantes latinoamericanos. Interesa la pregunta por los desplazamientos en territorios urbanos no sólo por sus implicancias en términos de la construcción de identidades ciudadanas, sino también por las formas del habitar translocal. Desde el estudio de las representaciones -mapas cognitivos- de inmigrantes peruanos de inicios del siglo XXI, habitantes de La Chimba en Santiago de Chile, se propone comprender estos desplazamientos locales y globales y sus implicancias en la construcción del habitar en nuestras ciudades. Se concluye que es la experiencia translocal del habitar -ni tan próximo ni tan lejano- la que construye la especificidad de estos territorios de frontera. Esto es, territorios diversos, heterogéneos y de culturas híbridas que, a través de desplazamientos reales e imaginarios, celebran y hacen posible la condición urbana de nuestras ciudades. Se propone así una antropología que excave en los silencios y en las memorias de aquellos itinerantes y desplazados sin los cuales la condición urbana nunca será.
\end{abstract}

Palabras claves: fronteras, inmigrantes, translocalidad, representación.

This article describes and interprets the construction of dwellings in border territories based on the translocal representations of Latin American immigrants. Patterns of migration in urban territories is of interest not only because of their relevance to the construction of civic identities but also translocal residential patterns. Starting with the study of representations -cognitive maps- of Peruvian immigrants of the XXI century, who were residents of La Chimba in Santiago de Chile, this paper explores these shifts and the local and global implications for the construction of dwellings in our cities. It concludes that it is the experience of translocal residence-neither as close nor as far- that builds the specificity of borderlands. That is, territories that are diverse, heterogeneous, and with hybrid cultures - through real and imaginary displacements-celebrate and enable the urban conditions of our cities. It therefore proposes an anthropology that digs into the silence and the memories of those itinerant and displaced individuals and groups without whose stories the urban condition will forever be incomplete.

Key words: Frontiers, migrants, translocation, representation.

Las representaciones de nosotros mismos en el mundo han estado íntimamente ligadas a las maneras en que ocupamos el espacio y hacemos territorio. Los individuos, las familias y los grupos sociales no habitan sus barrios y ciudades por el uso que puedan hacer de ellos, sino también porque son lugares de identificación, de distinción y ensoñación de mundos posibles. Las prácticas espaciales han sido históricamente una fuente esencial para la construcción de los significados identitarios. Es a esta condición de la identidad que se ha denominado "territorialidad o el poder de habitar" (Lefebvre 1976:62).

Sin embargo, y esta es la tesis que quisiera sostener, las identidades territoriales nacen, se crean y se transforman en fuente de poder y de control cultural, cuando los territorios que las cobijan son capaces, por su porosidad, de alimentar y ensanchar "el campo de lo posible" (Sartre 1962:13). La porosidad del territorio y su condición de translocalidad, esto es, de vaso comunicante es una condición a la construcción de las identidades, a la imaginación y a la posibilidad cierta de realización de la vita activa (Arendt 1961; 1983:46).

Este artículo se pregunta por la construcción y génesis de las identidades que se hacen al vaivén de los desplazamientos reales e imaginarios que dieron nacimiento y dan vida a nuestras ciudades y a nuestro Estado nación. Interesa la pregunta por los territorios y ciudades de fronteras múltiples y porosas no sólo por sus implicancias en términos

\footnotetext{
$\overline{1}$ Universidad Alberto Hurtado, Departamento de Antropología. Cienfuegos 46, Santiago, Chile. fmarquez@uahurtado.cl
} 
de los procesos de construcción de identidades ciudadanas y urbanas, sino también por sus consecuencias en las formas de un habitar translocal.

\section{Habitar y Transitar el Terruño}

Para hablar de Estado, de Nación y de ciudades debemos comenzar diciendo que si existe una condición esencial al hombre ésta es la de habitar, de estar vinculado a un territorio. Territorio como arraigo, territorio como vínculo y territorio como pertenencia que se hace justamente en el estar, en el transitar, en el relatar. Se habita cuando se construye (Heidegger 1993:13), cuando se echan raíces, cuando se hace historia; cuando las identidades y las expresiones ciudadanas en el terruño ganan lugar. Habitar un territorio es esencial a la definición de la condición urbana; de la misma manera como lo ha sido para nuestro Estado nación.

La territorialidad es el conjunto de relaciones $\mathrm{y}$ afectos que el individuo -en tanto miembro de una sociedad- teje con su entorno. Relaciones e historias que se inscriben en un espacio y en un tiempo (De Certau 1990:25), y donde las codificaciones norman el transcurrir de esta comunidad imaginada (Benedict 2000:39). Un territorio es por definición entonces, un espacio sociocultural porque en él se materializa el "nosotros"; el territorio es también un espacio político porque en él se definen y establecen las fronteras y los límites del Estado nación (Appadurai 1999:31; Clifford 1999:112).

Es indudable que junto a la irrupción de los flujos transnacionales, las geografías de las ciudades y de nuestros Estados forman un entramado de tensiones profundas y complejas. En la historia urbana, los flujos de inmigración siempre han tenido un sitial privilegiado en la conformación de nuestras ciudades. Ya sea para afirmar el nacimiento de un modo de vida urbano y cuestionar la coherencia de esa identidad urbana y nacional (Park 1930, 1999:16), problematizar las procesos de resignificación de las culturas inmigrantes en la ciudad (Gluckman 1963:3; Munizaga 1961:10) o bien celebrar la condición de diversidad que los flujos de inmigración otorgan a la ciudad como sociedad cosmopolita (Delgado 2007:65; Jacobs 1965, 1993:38; Mongin 2006:54; Simmel 1903, 1998:31, Jacobs 1965, 1993:38; Delgado 2007:65; Mongin 2006:54).

En este mismo sentido, los flujos inmigratorios siempre han sido leídos en su correlato espacial. Los flujos, como los ríos, dejan surcos en la ciudad, definiendo límites y fronteras de ocupación, de uso $\mathrm{y}$ alteridades diferenciadas. La figura del gueto y sus variantes constituye ciertamente la marca más clara y extrema de asentamiento de la extranjeridad. Desde el gueto judío en Praga; Little Italia y Chinatown en Chicago; el barrio de Saara en Río de Janeiro hasta las chimbas en ciudades como Antofagasta, Coquimbo o Santiago. Todos, en sus diferentes variantes, son territorios fronteras, entendidos como territorios que poseen un límite que los diferencia de la ciudad de los nativos; y a su vez, una impronta que los reúne en torno a una cultura, una etnia y un habitar signado por su condición de extranjeros. Esto es, habitantes que aun cuando se instalan en el territorio, en ellos está siempre el ideario y la práctica del movimiento potencial: ni tan próximos ni tan lejanos, son los habitantes que se instalan hoy para quedarse mañana (Simmel, 1998: 21).

\section{Territorios de fricción y contrafuegos}

En un contexto de mundialización creciente la pregunta por la dimensión política de la experiencia urbana y el devenir de la ciudad como polis y como símbolo de la emancipación se nos impone. ¿Quién pertenece a la ciudad? ¿Quién participa en ella? ¿Quién delibera? (Mongin 2006:250). Nuestras ciudades y la experiencia urbana como "zonas de fricción” (Delgado, 2007: 187; Joseph 2002:65) enfrentan a sus habitantes a la ambivalencia entre la discontinuidad fragmentada de sus espacios amurallados y los flujos que desdibujan y ensanchan sus fronteras (De Mattos 1999:345; Sassen 1999:85).

Nuestras ciudades así como nuestros Estados se pueblan de velocidades múltiples, de distancias y, por cierto, de desigualdades diversas. El imaginario de "ciudad de clase mundial" -Sao Paulo, Santiago, Lima, Bogotá, Caracas- coexiste con un campo imaginado residual y emergente que no siempre se condice con este imaginario de la ciudad translocal y global. Es el otro imaginario, el imaginario nostálgico de la comunidad bucólica, de la ciudad o barrio aldea con reminiscencias rurales y de tiempos lentos que se contrapone a la ciudad global, la ciudad del consumo, de los tiempos rápidos, de la estética de la seguridad, de los artefactos urbanos (aeropuertos, carreteras, mall). Son los pobladores que añoran las prácticas solidarias del campamento o la favela; las familias nostálgicas de sus barrios de infancia y la vida bucólica; los inmigrantes que 
guardan en su memoria y en su práctica cada uno de los detalles del habitar de la aldea de origen. Nostalgia mítica de una ciudad imaginada que más asemeja a una aldea que a la urbe moderna; a la comunidad (Gemeinschaft) que a la sociedad (Gesellschaft). Son imaginarios que conviven y se superponen; contradicción entre modernización y formas comunitarias en una ciudad privada, anónima y avasalladora vs. la localidad y el barrio como espacio de resguardo, encuentro y, a veces, actoría y ejercicio de reterritorialización.

Una mirada atenta a la historia de nuestras ciudades nos advierte que -a pesar de estos imaginarios y la "celebración del gueto" (Sennet 1975:78)- muchos territorios urbanos se caracterizaron justamente por su capacidad de acoger la fricción de la vida urbana y convocar a invitados de lugares diversos y lejanos. Flujos e intercambios de actores, de recursos, de ideas que unidos al apego al terruño abren nuevas formas a la construcción de la vita activa en la ciudad. Territorios que, a diferencia de nuestros barrios segregados, lograron y logran en el movimiento y en el compromiso con lo propio y lo ajeno, abrir posibilidades y contrafuegos a la "comunidad purificada" (Sennet 1975:89) que vive enquistada en nuestra sociedad.

Indagar en esta dimensión, es decir, en la capacidad de los territorios de constituirse -en un contexto de movimientos y migraciones crecientesen espacios de cobijo, de contrapoderes y ejercicio ciudadano; comprender y caracterizar estas translocalidades urbanas como espacios de circulación de bienes, de culturas, de contrapuntos, debates $\mathrm{y}$ vasos comunicantes se nos ha vuelto una tarea ineludible al quehacer de la antropología.

\section{Enfoque Metodológico}

Esta investigación se sitúa conceptual y metodológicamente en la experiencia urbana translocal del inmigrante latinoamericano del siglo XXI, en un territorio de frontera, como es La Chimba de Santiago de Chile. Se observan las representaciones, y a través de ellas, los trayectos y prácticas que conforman un territorio de pertenencias translocales en la ciudad.

La premisa es que para los inmigrantes, el territorio que los acoge, no se experimenta y representa sólo como el territorio del aquí y el ahora, sino como espacio significante que se lee y representa a partir de los significados de la experiencia del habitar en el lugar de origen. Es desde este diálogo entre experiencias del habitar que se conforma una representación del habitar translocal.

Se observan dos aspectos básicos de la representación espacial y geográfica de la vida cotidiana de los migrantes: (i) La construcción de escenarios de comportamientos del migrante (lugares donde se despliega la práctica del habitar; lugar de origen y lugar de destino); (ii) y el desarrollo de prácticas culturales que guían el desplazamiento y construyen principios del habitar del migrante en este territorio de frontera translocal. (iii) Ambos -escenarios y prácticas- llenan de contenido geográfico significativo la vida cotidiana, definiendo la representación del habitat configurativo de nuestra ciudad (De Castro 2005:26).

La investigación, fundamentalmente cualitativa, se vale de mapas cognitivos realizados por inmigrantes peruanos que habitan actualmente (2010) $\mathrm{La}$ Chimba. La cartografía simbólica (a diferencia de la cartografía física), expresada en la construcción de croquis, da cuenta de los límites metafóricos e imaginados, de los hitos y demarcaciones que indican y unen territorios a una memoria colectiva y a una manera de hacer las cosas que enlaza y da sentido (De Castro 1997, 2005:37).

El objetivo es hacer una lectura comprensiva del proceso de representación y configuración del hábitat translocal desde estos inmigrantes. Mediante los dibujos se representa la relación significante del sujeto a su espacio. La palabra y el relato de vida constituyen el soporte de esta cartografía simbólica, mapas mentales de los espacios habitados y las prácticas asociadas a ellos.

En este artículo se presenta una síntesis del análisis de 60 mapas cognitivos correspondientes a 20 inmigrantes y habitantes de La Chimba. A cada migrante se le solicitó realizar tres croquis correspondientes a la representación de la ciudad de Santiago, su barrio de origen en Perú y el barrio de acogida en La Chimba, Chile (Figura 1).

El trabajo etnográfico se focalizó en las comunas de Recoleta e Independencia, en el radio que la literatura e historiografía indican como La Chimba: por el sur, Avenida Domingo Santa María; al norte, Avenida México; al oriente calle Loreto, al poniente Avenida Fermín Vivaceta. El universo de informantes corresponde a 20 inmigrantes peruanos, diez hombres y diez mujeres, con un rango de diez a un año de residencia en Chile. Todos habitan en $\mathrm{La}$ Chimba, trabajan en oficios y servicios vinculados a 


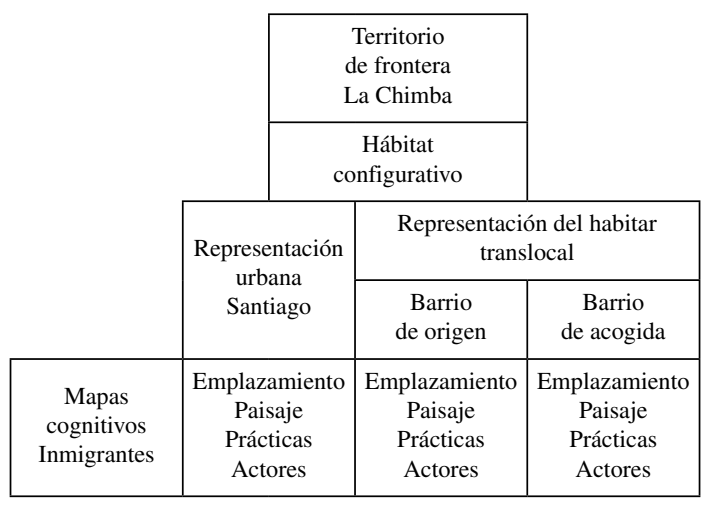

Figura 1. Modelo de análisis, dimensiones (elaboración de la autora Fondecyt $\mathrm{N}^{\circ}$ 1095083).

Model of analysis, dimensions (illustration by author Fondecyt $N^{o}$ 1095083).

este sector de la ciudad (comercio, mercado, trabajo informal, entre otros) (Figura 2).

\section{Santiago desde la Otra Banda}

La Chimba-la otra banda en lengua quechua-, al norte del río Mapocho, ha sido históricamente nuestro "otro lado". Desde su origen, en la Colonia, se instala material y simbólicamente lo que el centro de la ciudad no quiere en su interior: los cementerios, los hospitales, el mercado y los inmigrantes empobrecidos en busca de mejor fortuna. La Chimba, aldea de indios, ha sido durante cuatro siglos y medio, frontera, trastienda, pero también cobijo y lugar de la diversidad. Si el centro de Santiago es la cara de la legalidad y la civilidad, La Chimba ha sido contracara y reverso; una ciudadela paralela al otro lado del río. Entre avenida Independencia y calle Loreto, oleadas de migrantes se han instalado históricamente desde inicios del siglo XX, consolidando su impronta de territorio mosaico: árabes que llegaron escapando del Imperio Turco Otomano; españoles refugiados de la guerra civil; palestinos huyendo tras la creación del Estado de Israel; coreanos atraídos por la liberalización de la economía chilena; y más recientemente, latinoamericanos empobrecidos en busca de un trabajo para sobrevivir.

En la decisión de estos inmigrantes de instalarse en La Chimba juegan a favor los bajos precios de los terrenos y las viviendas, la cercanía a sus iguales (otros inmigrantes) y las múltiples oportunidades de trabajo que les ofrece este distrito comercial.

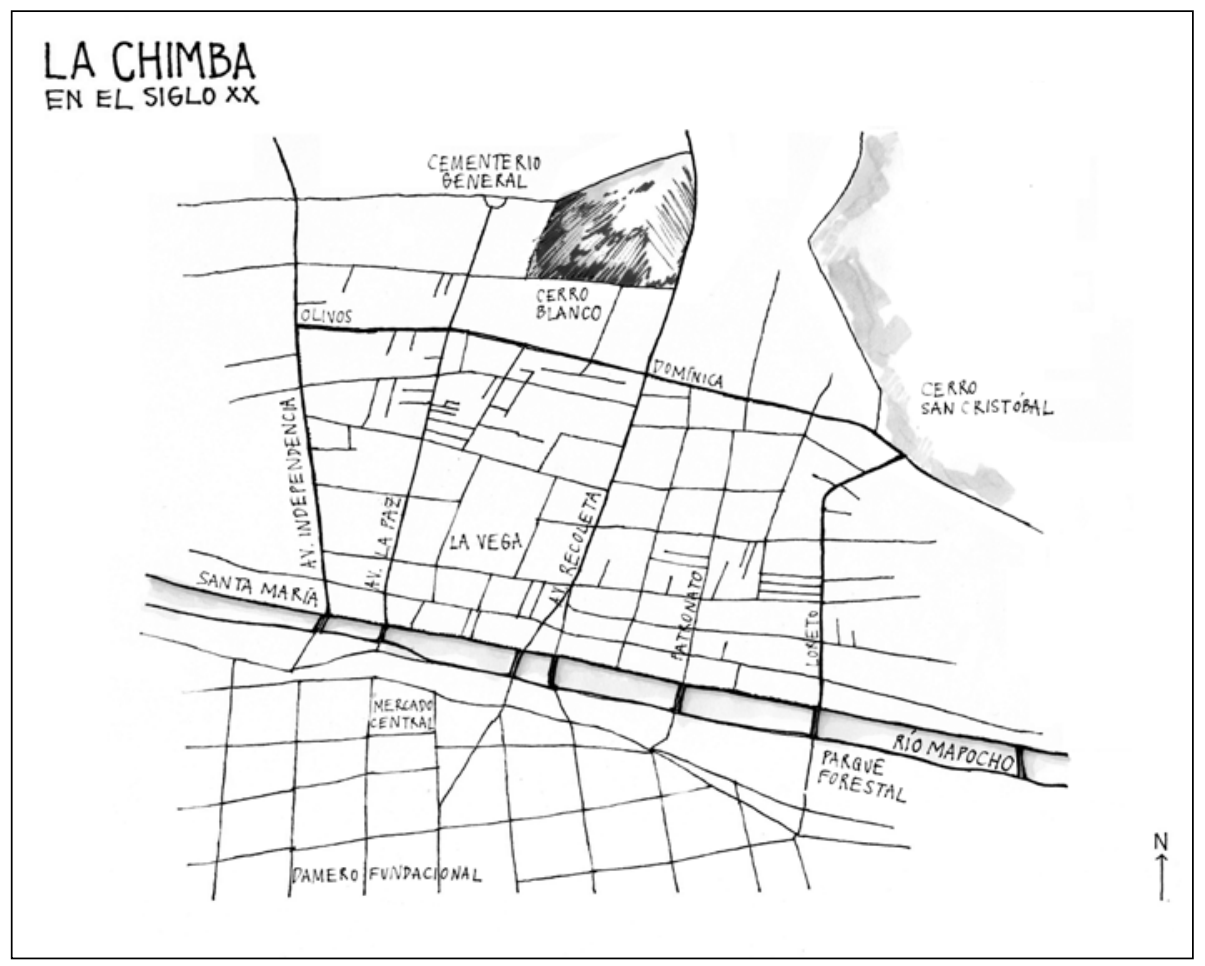

Figura 2. La Chimba del siglo XX (elaboración R. Arriagada, Fondecyt $N^{\circ} 1095083$ ).

La Chimba of the 20th century (illustration by R. Arriagada, Fondecyt $N^{o} 1095083$ ). 
Si bien con la instalación del mercado de La Vega, el año 1895 , el carácter comercial y productivo de La Chimba había adquirido especial fuerza con la llegada de comerciantes y pequeños industriales palestinos, el año 1948, este carácter termina por consolidarse. Pero es a partir de los años ochenta -con la crisis económica del país y la llegada de comerciantes coreanos- que se genera un proceso abrupto de densificación de la superficie con fines comerciales y residenciales con la consecuente tugurización de su arquitectura. Junto al auge del comercio comienzan a tomar forma los patrones morfológicos de polifuncionalidad que hoy caracterizan a La Chimba. El principio funcional de albergar simultáneamente locales comerciales, viviendas y fábricas textiles fue el que primó en este proceso, superponiéndose a regulaciones ordenadas de una autoridad central que intentará planificar y ordenar el sector. Es la actividad laboral y comercial el gran eje que se impone y articula esta compleja trama de diversidad etnocultural, creando un espacio de convivencia de actores que transitan cotidianamente por sus calles y tiendas.

En la cartografía histórica de Santiago, que contiene y expresa los idearios y narrativas dominantes de las utopías urbanas de su tiempo, La
Chimba siempre fue representada desde el centro. Es decir, desde el lado sur del río Mapocho (ver Figura 2). Así ocurrió con los planos de Alonso de Ovalle (1646), de Frezier (1712), Gay (1834), Ansart (1872), entre muchos otros (Martínez 2007:23-43). En estos términos, podríamos decir que La Chimba, para la ciudad propia, siempre ha estado al "otro lado" del ideario de la ciudad deseada.

En las representaciones cartográficas de los habitantes de La Chimba, en cambio, la mirada se invierte. Y es La Chimba la que desde el norte observa hacia el sur, hacia el casco histórico de Santiago. En la parte inferior del mapa se sitúa el punto "desde" donde se viene o se está (La Chimba) y la parte superior la dirección "hacia" donde se va (el centro de Santiago). Siempre el norte abajo, como "puerta de entrada" hacia el sur, el centro de Santiago.

Tal como se muestra en el siguiente mapa (Figura 3), un hombre inmigrante representa en el extremo inferior (el norte) el mercado de La Chimba; desde allí observa hacia el centro de Santiago. Como límite e interfase, dividiendo el mapa en dos, el río y su gran puente de Los Carros. Para que no quede duda, escribe sobre su dibujo "debajo del puente está el río Mapocho". En el extremo superior está

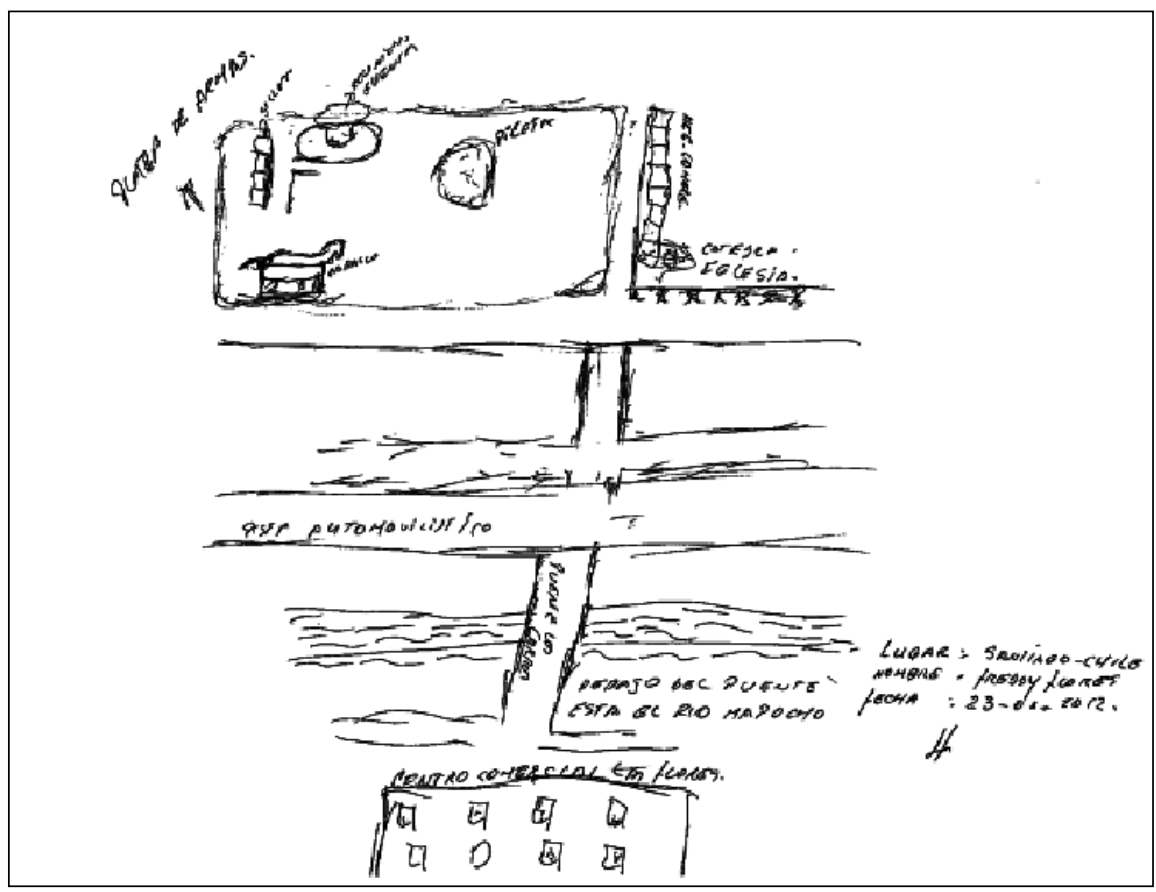

Figura 3 La ciudad de Santiago según hombre inmigrante peruano (fuente: entrevista a P. Álvarez, Fondecyt No 1095083). The city of Santiago according to an immigrant Peruvian man (source: interview with P. Álvarez, Fondecyt $N^{\circ} 1095083$ ). 


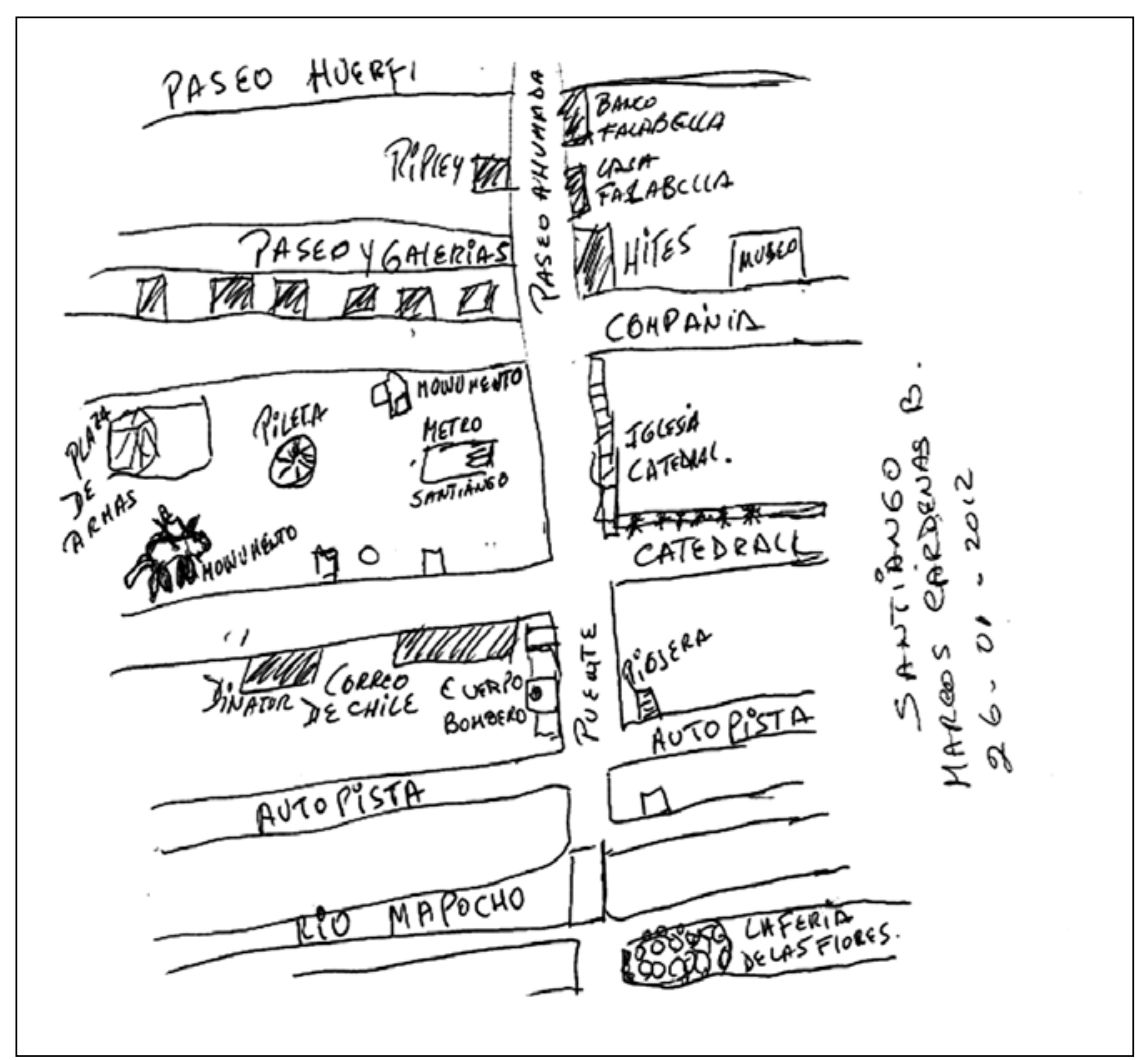

Figura 4. La ciudad de Santiago según inmigrante peruano (fuente: entrevista a P. Álvarez, Fondecyt No 1095083, 2012).

The city of Santiago according to an immigrant Peruvian man (source: interview with P. Álvarez, Fondecyt $N^{o} 1095083,2012$ ).

el sur, la ciudad con sus calles, la Plaza de Armas y la catedral con sus muros de piedra, lugar de encuentro de inmigrantes. Representación que habla de un deseo de integración a la vida urbana, pero sin perder de vista el lugar desde donde se parte, La Chimba, al otro lado del río.

En este ejercicio de representación, la ciudad de Santiago es signada y representada siempre desde sus afanes y trayectos cotidianos, en especial aquellos que dicen relación con el trabajo y la obtención de recursos para la subsistencia. Afanes y tareas que en su mayoría se realizan desde La Chimba, pero siempre mirando hacia el centro que provee y a menudo demanda sus servicios y productos. En el croquis siguiente (Figura 4), las grandes casas comerciales y de crédito son dibujadas con precisión, al igual que la Plaza de Armas y el puente que une La Chimba con el centro de la ciudad y su paseo peatonal Ahumada.

Mirado desde el norte, del otro lado del río, Santiago se ofrece como promesa de bienestar y calidad de vida. Sin embargo, como ellos mismos dicen, para cruzar los puentes, "hay que ser un guerrero" y estar dispuesto a correr el riesgo de no regresar. Sin embargo, en el centro está la llamada "Pequeña Lima"; a un costado de la catedral, los "guerreros" se apertrechan y allí despliegan sus contactos y redes que los llevarán a encontrar un trabajo. Los grandes muros de piedra de la catedral son el nodo del encuentro entre iguales, allí se tejen las conversaciones, intercambian datos y amarran las complejas redes de mutua ayuda (Figura 5).

\section{Lugar de Origen, Lugar de Destino: Representaciones Translocales}

Los siguientes mapas son coincidentes en dos aspectos: en el lugar de origen está la familia y la adscripción a lo propio. En el lugar de destino, las oportunidades, el trabajo y la nostalgia. Las topofilias, esto es, los afectos y el apego a ambos lugares, se construyen en este ir y venir entre lo que se deja y lo que se obtiene, pero sin olvidar lo dejado. Topofilias translocales, ni tan lejos ni tan cerca, en cada lugar 


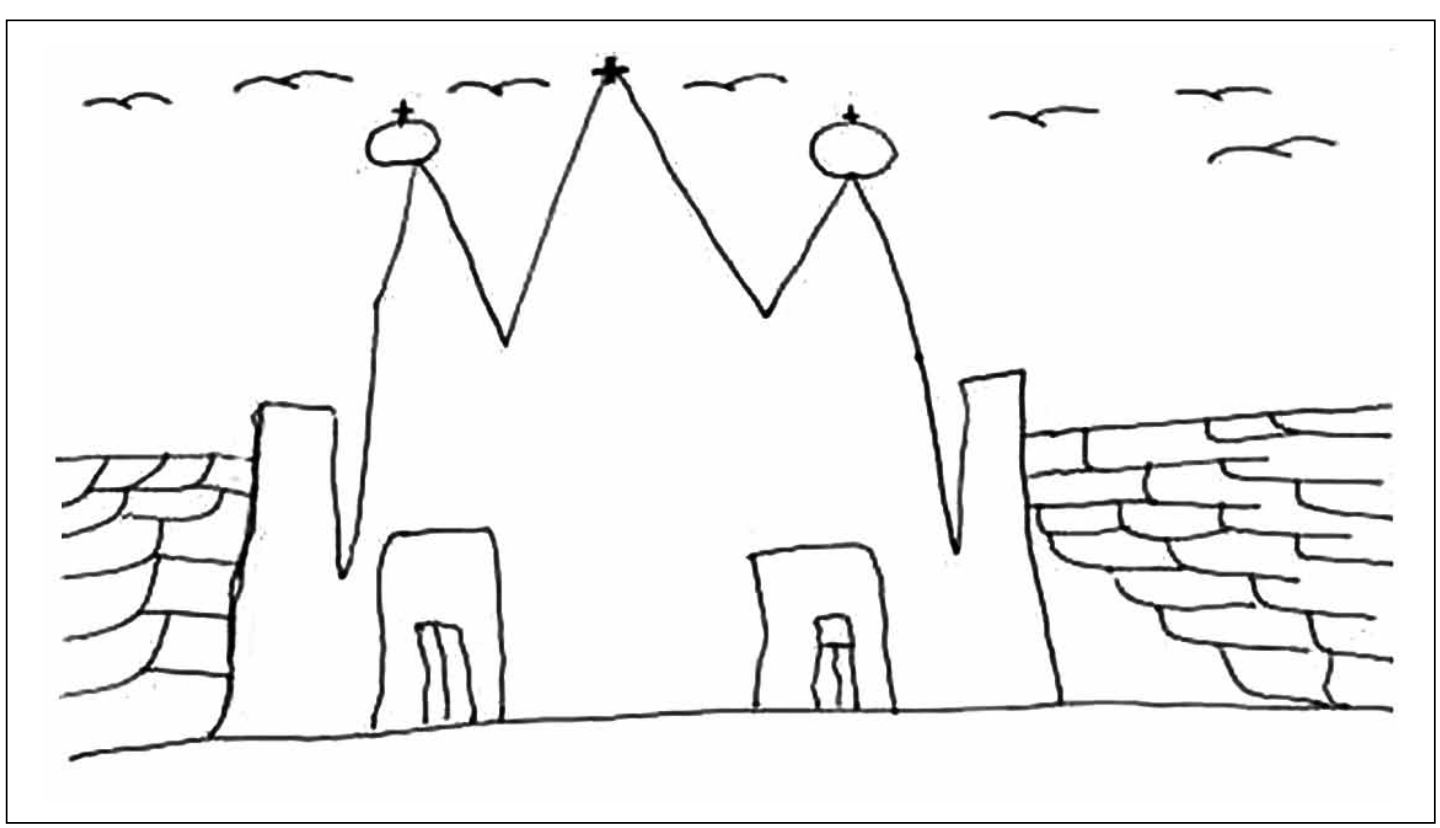

Figura 5. La ciudad de Santiago, la catedral, mujer inmigrante peruana (fuente: entrevista a S. Granados, Fondecyt $N^{\circ} 1095083$, 2010). The city of Santiago, the cathedral, female Peruvian immigrant (source: interview with S. Granados, Fondecyt $N^{o} 1095083,2010$ ).

los afectos se tejen diferenciadamente, pero siempre unidos por un delicado vínculo de reconocimiento entre el lugar de origen y el lugar que los acoge. A pesar de la distancia, en las representaciones de ambos territorios, así como se descubren fuertes diferencias, también hay semejanzas.

En la Figura 6, al igual que en muchas otras, el lugar de origen -Puno- se representa no solo en sus detalles (construcciones de ladrillos y barcazas), sino también en el paisaje que lo rodea: el cielo estrellado, los cerros, el lago Titicaca, sus calles y viviendas estrechamente emplazadas. Un paisaje que habla de armonía, tranquilidad y como bien dice en la frase escrita en el borde inferior del mapa: "Puno, zona turística". Esto es, lugar de reconocimiento a la mirada del extranjero. Mientras Puno se representa en su magnificencia y perspectiva -a la manera de una foto que se mira a distancia-, el lugar de acogida, La Chimba, aparece sin perspectiva ni paisaje que lo contextualice. Si bien las casas, bodegas y árboles son dibujados con esmero y detalle, no hay perspectiva ni escenografía alguna; apenas las calles que ordenan el habitar y el deambular por el barrio. Eso es La Chimba, presente del habitar.

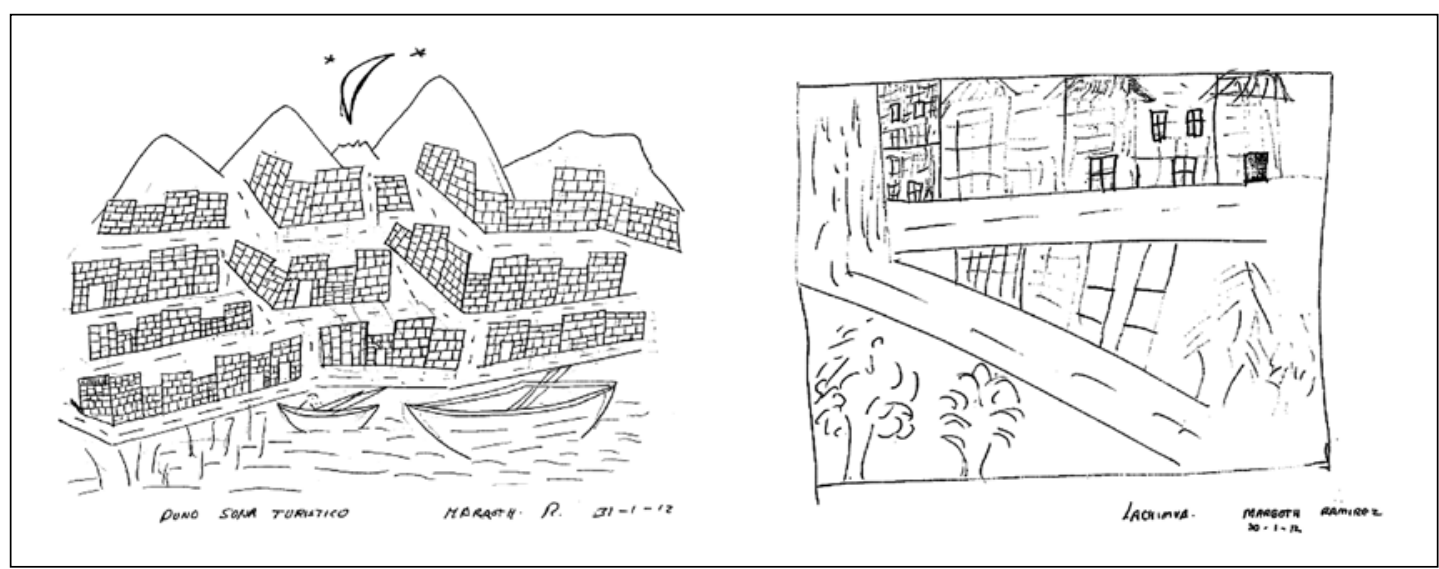

Figura 6. Puno en Perú y La Chimba en Chile según inmigrante peruana (fuente: entrevista a P. Álvarez, Fondecyt No 1095083, 2011). Puno in Peru and La Chimba in Chile according to an immigrant Peruvian woman (source: interview with P. Álvarez, Fondecyt $\left.N^{o} 1095083,2011\right)$. 
En la siguiente representación (Figura 7), nuevamente el lugar de origen, esta vez es el paisaje del poblado Las Minas en Perú. Allí la mujer se representa en su casa "donde crecí y me crié". El entorno y su paisaje es bucólico, montes, árboles, animales, una cruz en lo alto de un cerro y más árboles. La Chimba en cambio, lugar de destino, se representa de manera concisa: Al centro la mujer y su carro de venta de alimentos, el quitasol que la protege y el cliente con un billete en la mano; como trasfondo, apenas unos camiones que portan los alimentos, probablemente al mercado de La Vega.

En los mapas siguientes (Figuras 8 y 9) se repite la misma representación. En el pueblo de origen, San Martín de Porres en Barrio Salcedo, la sociabilidad del barrio, un equipo de música y los vecinos que bailan en la calle. En La Chimba, la racionalidad de la vida cotidiana y familiar es representada a través de un preciso circuito de producción y reproducción de la vida cotidiana. $\mathrm{La}$ rutina es siempre la misma: A mediodía el hombre lleva a su mujer el alimento, ella vende en su carro, luego él da almuerzo a sus hijos en la casa, y en la tarde practica su deporte, karate; así todos los días. Una rutina centrada en el núcleo cercano, donde el vecindario y la sociabilidad desaparecen.

En la siguiente representación, Iquitos, a la manera de una ciudadela ideal y utópica, el mundo

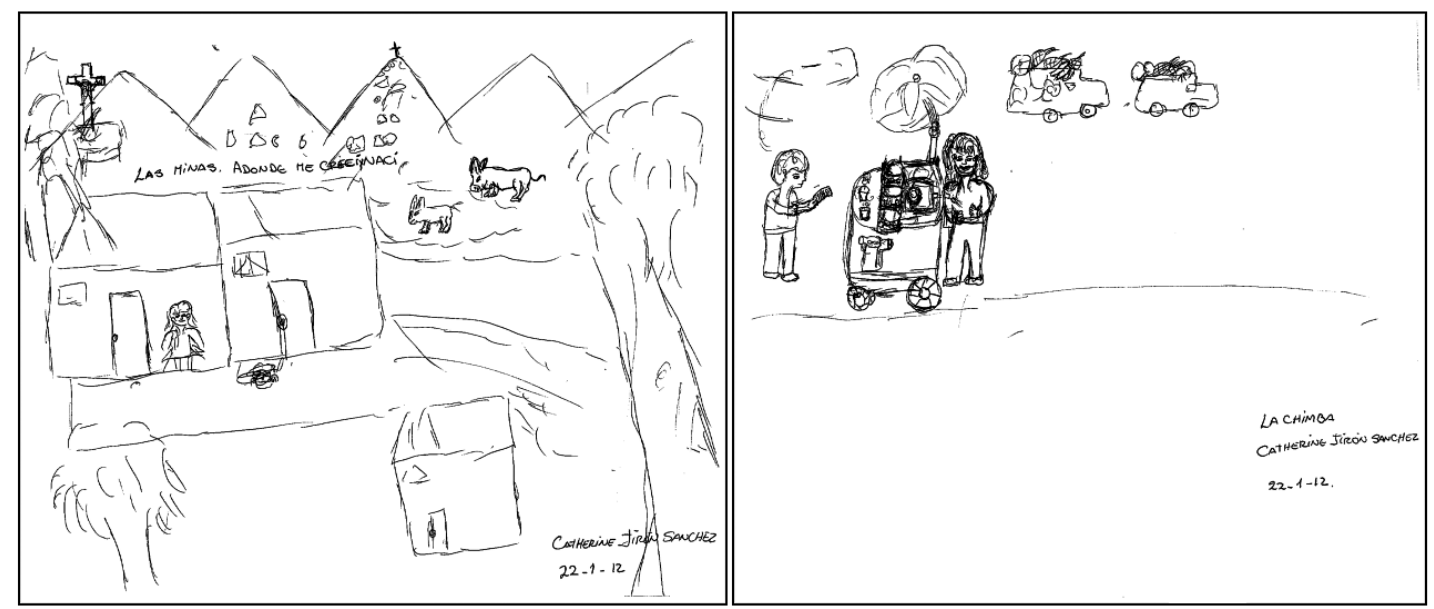

Figura 7. Las Minas en Perú y La Chimba en Chile según inmigrante peruana (fuente: entrevista a P. Álvarez, Fondecyt No 1095083 , 2011).

The Mines in Peru and La Chimba in Chile according to an immigrant Peruvian woman (source: interview with P. Álvarez, Fondecyt $N^{o} 1095083,2011$ ).
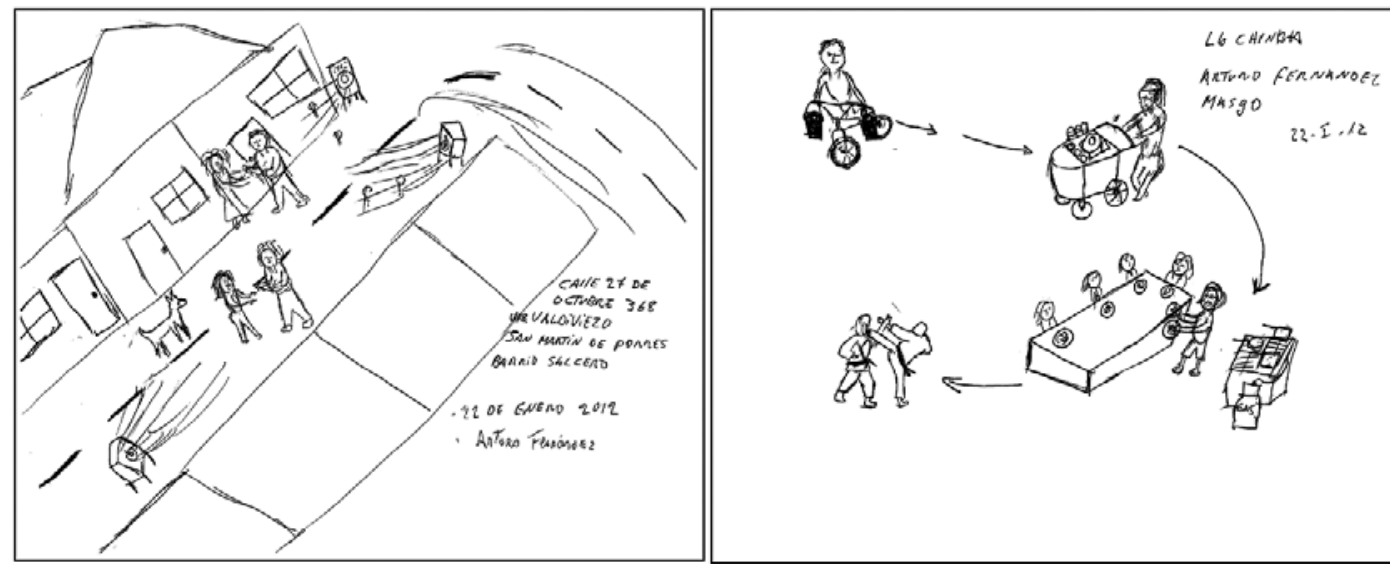

Figura 8. San Martín de Porres en Perú y La Chimba en Chile según inmigrante peruano (fuente: entrevista a P. Álvarez, Fondecyt $\mathrm{N}^{\circ} 1095083,2012$ ).

San Martín de Porres in Peru and La Chimba in Chile according to an immigrant Peruvian man (source: Interview with P. Álvarez, Fondecyt $N^{o} 1095083,2012$ ). 


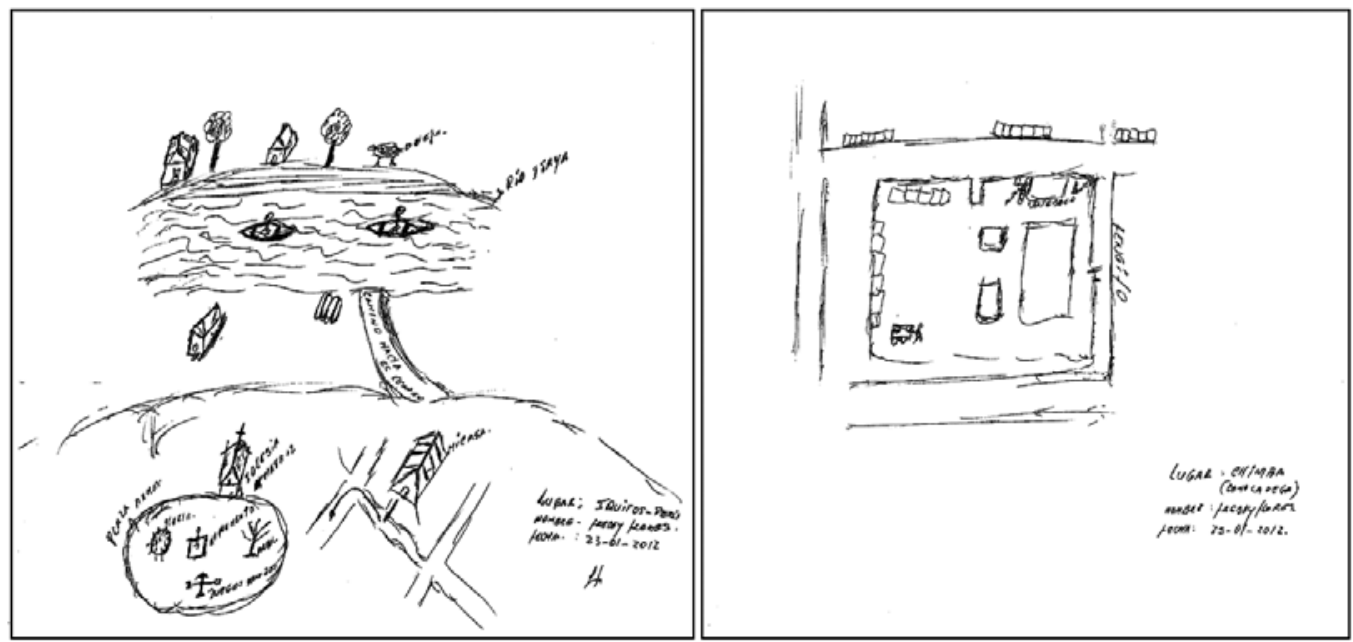

Figura 9. Iquitos, Perú y La Chimba, Chile según inmigrante peruano (fuente: entrevista P. Álvarez, Fondecyt No 1095083, 2012). Iquitos in Peru and La Chimba in Chile according to an immigrant Peruvian (source: Interview with P. Álvarez, Fondecyt $N^{o} 1095083,2012$ )

parece contenido en ella. Todo está ahí, el río, la plaza, la propia casa, la iglesia, las calles, la vida entera. En La Chimba en cambio, la mirada de la representación pierde perspectiva y se centra en la cuadrícula que contiene las bodegas, y entre todas ellas, la propia figura empujando el carro de alimentos que se ofrecen en el mercado.

\section{Ocupar el Territorio Translocal}

Diversos estudios (Grimson, 2011:11; Reguillo y Godoy 2005:12;) advierten como frente al movimiento de poblaciones y el desdibujamiento de las fronteras identitarias y territoriales nacen esfuerzos de reterritorialización. Esto es, de construcción de prácticas segmentadas para fijar el propio terruño; pero también de representaciones translocales para saldar la distancia que separa el lugar de origen del lugar de destino. En un contexto de velocidades y flujos que desdibujan el espacio de lo propio y de las pertenencias cercanas, los inmigrantes logran crear -a través de sus prácticas y representaciones- nuevos lugares, nuevas jerarquías y nuevos (des)órdenes.

Estas representaciones cartográficas de inmigrantes (ver figuras anteriores) nos advierten que la deslocalización de la propia experiencia puede crear procesos de reterritorialización del habitar, entendidos como imaginarios de autonomía, poder o soberanía de recursos sobre los lugares. La diversidad de estas representaciones translocales tiende a confundir las narrativas que intentan naturalizar y homogeneizar tales historias locales, vecinales e incluso de la ciudad central.

Como bien lo señalan estos croquis, la ciudad del centro bien puede ser remirada y repensada desde la "otra orilla", del lugar donde la mirada oficial nunca se la representó. El inmigrante y extranjero, no solo desnaturaliza las representaciones desde el centro, sino también subvierte, resitúa y resignifica el lugar de la mirada. A su vez, el lugar que se creía atrás -Perú-, porque es mirado a distancia, adquiere perspectiva y con ello alimenta el afán cotidiano de un lugar-La Chimba- que apenas se conoce.

El ejercicio de representación translocal del habitar nos informa de la relevancia que el territorio de origen posee en las prácticas y la configuración del nuevo hábitat. Mientras en el terruño se adscriben las pertenencias y los afectos más cercanos, en el territorio de acogida se destacan y representan sus recursos a la propia subsistencia (el mercado, el trabajo, la conectividad). Si en Perú se deja atrás el paisaje, la cordillera, el vecindario, en La Chimba no hay más perspectiva que el aquí y el ahora en el trabajo. La ciudad, siempre mirada desde el territorio de cobijo, es decir, al norte del río, aparece como la promesa de la modernidad, lejana, ajena y a ratos invisibilizada tras el muro de la catedral, el aeropuerto o el mismo mercado de La Vega. Como la figura de El Dorado o la Ciudad de los Césares, Santiago no es sino un referente lejano, de grandes tiendas, centros comerciales, paseos y vitrinas. Pero donde se habita, donde se trabaja es en La Chimba, al norte del río y sus puentes. A la ciudad se cruza 
siempre, sabiendo que la posibilidad de regresar al cobijo, está allí, al otro lado del río.

Las representaciones de estos nuevos habitantes de la ciudad hablan de prácticas y espacios transnacionales que pueden ser también lugares de resistencia, como representantes de culturas híbridas, de identidades multiposicionadas, de prácticas de fronteras como estrategias para escapar al control de la ciudad ordenada a la manera del ideario hegemónico. Representaciones translocales, que reformulan el espacio social, político y urbano; ya no desde las categorías de marginales o excluidos, sino como ciudadanos que crean un espacio más fluido e interconectado entre el adentro y el afuera, ampliando así la frontera y las disputas posibles en su interior. Así también nos advierte de la fuerza y capacidad de estos territorios de frontera e intersticio -las chimbas- para acoger, blindar e interconectar a quienes en un movimiento simultáneo van y vienen en este mundo de lo propio y lo ajeno (Bonfil 1995:81).

Pensar el espacio transnacional como fluido y fragmentado, al interior de nuestras ciudades latinoamericanas, complementa los estudios de la soberanía y ciudadanía en la reconsideración de los Estados Nación como entidad espacial y territorial. Así como la mayor peculiaridad del Estado Nación moderno fue la idea de que las fronteras territoriales podían mantener indefinidamente la fábula de la singularidad étnica (Bhabha 2002:34); podríamos señalar que la peculiaridad de nuestras segregadas ciudades latinoamericanas fue la idea que las fronteras territoriales podrían -a través del blindaje y amurallamiento- mantener la ilusión de la ciudad propia, como principio de orden y control del habitar. Ambas ideas hoy se han vuelto insostenibles. La primera por la evidencia de las disputas de espacios entre diásporas de inmigrantes y ciudades, que en el caso de la ciudad de Santiago ha pasado en pocos años a ser receptora o destino de inmigración latinoamericana. Asimismo, las evidencias históricas señalan que el ciudadano de nuestra urbe transita, transgrede las fronteras, conformando un ancho corredor que va entre el lugar de origen y la ciudad de destino. Pero en la ciudad de destino, el espacio de acogida, como trinchera y cobijo, opera como territorio translocal y fronterizo entre la ciudad propia y la ciudad bárbara. El problema en este sentido, no es el pluralismo cultural, la diversidad de identidades en sí, sino la tensión entre estas diversidades que transitan y transgreden fronteras y murallas; subvirtiendo el ideario de una ciudad única y homogénea.

\section{Representaciones de Soberanías Translocales}

En la historia de la teoría cultural, el territorio y la territorialidad han tenido un papel importante: la idea que las culturas son coherentes, circunscritas, contiguas y persistentes siempre ha estado avalado por una percepción de que es en la localidad que las identidades se constituyen. Y de que las realidades territoriales confinan y determinan a la vez las costumbres y las culturas. Existe una percepción generalizada que las culturas están condicionadas a demandar espacios de lealtades y reconocimiento (Bhabha 2002:24; Clifford 1999:36; Grimson 2011:115). Las prácticas espaciales han sido la principal fuente de evidencia y análisis para la sociología y la antropología urbana. Pensar los territorios - poblaciones, barrios, villas- desde sus porosidades, vasos comunicantes y flujos de capitales, de bienes, de culturas y de actores exige un esfuerzo por resituar la mirada. Esto es, una aproximación crítica a la producción del espacio urbano más allá de las estrechas fronteras de la ciudad y su cultura.

La pregunta es cómo hacer factible una etnografía del relato identitario translocal si la autoridad y la práctica etnográfica se construyen como un relato in situ, de historias, continuidades, coherencias... La pregunta por la construcción de lo local y su articulación con lo global reorienta la práctica de la antropología contemporánea. Hoy, los estudios de desplazamientos de las culturas nos alertan sobre el poder de los individuos en su capacidad simultánea de, por una parte, territorializar paisajes de la memoria (como resguardo y reactualización) y, por otra, de desterritorializar esos mismos arraigos.

Los movimientos de culturas, capital y trabajo existen desde que los viajes inauguran la búsqueda de nuevos horizontes. Pero se viaja para regresar, decía Rilke. Los espacios recorridos así como generan nuevas prácticas culturales, nuevas identidades, alteridades, poderes, culturas y conocimientos, también reorientan el camino de regreso y relectura de lo propio. En antropología el viaje y el desplazamiento han sido leídos desde los lazos y tensiones que se construyen con el lugar de acogida y el lugar de origen; el problema es el desarraigo. La pregunta por la génesis de nuevas configuraciones culturales, identitarias y de soberanías (Bataille 1996:4) en estos espacios transnacionales es un trabajo que hay 
que realizar. Etnografías cuyo objetivo se oriente a comprender la multilocalidad y la polifonía como recursos en la construcción de soberanías que se hacen en la paradoja del movimiento y la transgresión a la mirada única.

Una etnografía que describa este mundo de minorías y migrantes que fluyen entre Estados y territorios; pero también que asuma que no hay ejercicio ciudadano y citadino posible en territorios impermeables al movimiento, a la diversidad, a la reactualización de sus derechos. Una etnografía abierta a la comprensión de soberanías móviles, translocales que, a su vez, enriquecen y alimentan el campo de la imaginación y el ejercicio ciudadano (Appadurai 1996). Una etnografía de las rutas e itinerarios entre vecindarios, no como aldeas de fronteras y murallas, sino del movimiento y del viaje como permanente búsqueda política. Las evidencias etnográficas nos indican que no existe reterritorialización posible si los ciudadanos viajeros no evocan e imaginan espacios y tiempos para ser significados colectivamente.

Una etnografía que no se reduzca al develamiento de las estructuras de poder, sino también a la comprensión de la resistencia cotidiana hacia las formas espaciales del ordenamiento y control social. A la manera de Michel de Certau (1990:26), podríamos decir que la manera de operar y de relatar de las personas constituye el sentido por el cual los habitantes se reapropian del espacio. Prácticas articuladas a la cotidianeidad y a las tácticas clandestinas desde donde se desarrolla una teoría del espacio vivenciado que elude el disciplinamiento impuesto por la planificación urbana.

La pregunta por el ejercicio ciudadano nos indica que más que el nómada como movimiento permanente y subversión a los espacios del control, de lo que se trata es de poder asir aquellas dimensiones de la cotidianeidad que permiten constituir una cultura del ciudadano que, sin renunciar al terruño, se abra en sus prácticas e imaginación a universos siempre posibles de explorar. Ni tan próximo ni tan lejos, un ciudadano que se construye en esta relación de pertenencia fronteriza, entendida como esa línea indeleble, pero porosa que se puede cruzar y mirar de uno y otro lado.

El desafío es visualizar las culturas en sus múltiples conexiones externas de modo que aparezca el cronotopo de la cultura (entendido como escena que organiza el tiempo y el espacio), como sitio de viaje, de intercambios y residencia... La mirada de la antropología debe entonces orientarse a comprender las historicidades allí construidas y disputadas, los sitios de desplazamientos, interferencias e interacción. Para ello por cierto necesitamos otro tiempo de escritura que pueda abrirse a las representaciones ambivalentes de tiempo y lugar que constituyen la experiencia moderna del habitar. El espacio del habitar del inmigrante nunca es lineal ni horizontal. ¿Cómo describir entonces desde la etnografía las diferencias y las formas culturales que compiten para ser representadas en ese tiempo y espacio que es la cultura urbana?

La construcción de contra narrativas de la ciudad, que evocan y borran sus fronteras totalizantes, homogeneizantes, puede ser un camino fructífero. Ejercicio etnográfico, que abra la mirada hacia el ágora e impida que las ciudades se cubran de identidades esencialistas donde se imponga un discurso homogéneo del progreso, de los cronos y los topos de las narrativas sociales.

El desafío de la representación etnográfica es el retrato y comprensión de estos encuentros históricos locales y globales con todo lo que ellos poseen de deliberación, dominación y resistencia. Una etnografía de las experiencias híbridas, cosmopolitas y enraizadas que abran caminos hacia la comprensión de nuestras ciudades como ágoras de la translocalidad.

Agradecimientos: Este texto reúne parte de los planteamientos teóricos y resultados empíricos de la investigación de la autora "La Ciudad de los Otros. Inmigrantes en territorios de frontera: La Chimba en el siglo XX", Fondecyt No 1095083. Este artículo se alimenta a su vez de las sugerencias y precisiones realizadas por los evaluadores de Chungara. 


\section{Referencias Citadas}

Appadurai, A. 1999. Soberanía sin territorialidad: notas para una geografía posnacional. Revista Nueva Sociedad 163:109-124.

Arendt, H. 1983 [1961]. La Condition de l'Homme Moderne. Calmann-Lévy, Paris.

Bataille, G. 1996. Lo que Entiendo por Soberanía. Paidós, Barcelona.

Bhabha, H. 2002. El Lugar de la Cultura. Ed. Manantial, Buenos Aires.

Clifford, J. 1999. Itinerarios Transculturales. Ed. Gedisa, Barcelona.

De Certeau, M., P. Mayol y L. Mayol 1990. L'invention du Quotidien, 1: Arts de faire. Gallimard, Paris.

De Mattos, C. 1999. Santiago de Chile, globalización y expansión metropolitana: lo que existía sigue existiendo. Revista Eure 76:507-542.

Delgado, M. 2007. El animal público. Para una antropología de los espacios urbanos. Anagrama, Barcelona.

Gluckman, M. 1963. Order and Rebellion in Tribal Africa. London: Cohen and West.

Grimson, A. 2011. Los límites de la cultura. Crítica de las teorías de la identidad, Ed. siglo XXI, Buenos Aires.

Heidegger, M. 1993. El Ser y el Tiempo. F. de C. E., México. Jacobs, J. 1993. The Death and Life of Great American Cities. New York, Modern Library.
Joseph, I. 2002. El Transeúnte y el Espacio Urbano: Ensayo sobre la Dispersión del Espacio Público. Gedisa, Barcelona.

Lefebvre, H. 1976. Espacio y Política: el Derecho a la Ciudad, Península, Barcelona.

Mongin, O. 2006. La Condición Urbana: La Ciudad a la Hora de la Mundialización, Ed. Paidós, Buenos Aires.

Munizaga, C. 1961. Estructuras transicionales en la migración de araucanos de hoy a las ciudades. Publicaciones Centro de Estudios Antropológicos, U. Chile, № 12(6). Santiago.

Park, R.E. 1999. La Ciudad y otros Ensayos de Ecología Urbana, Del Sebal, Madrid.

Reguillo, R. y M. Godoy. 2005. Ciudades Translocales: Espacios, Flujo, Representación. Perspectivas desde las Américas. Ed. Iteso, México.

Sartre. J.P. 1962. Colonialismo y Neocolonialismo. Losada, Buenos Aires.

Sassen, S. 1999. La Ciudad Global. Nueva York, Londres, Tokio. Eudeba. Buenos Aires.

Sennet, R. 1975. Vida Urbana e Identidad Personal. Península, Barcelona.

Simmel, G. 1998. Las grandes urbes y la vida del espíritu, En El Individuo y la Libertad, Ensayos de Crítica de la Cultura, Península, Barcelona, España. 